\title{
THEMATIC PROGRESSION PATTERNS OF SHORT STORY THE BLACK CAT
}

\author{
Dewi Fatmawati, Tengku Silvana Sinar, Rohani Ganie, Muhammad Yusuf ${ }^{4}$ \\ University of Sumatera Utara, \\ Medan, Indonesia \\ E-mail: dewifatma1312@gmail.com
}

Received: 11 March 2019

Accepted: 27 May 2019

\begin{abstract}
This study attempts to investigate thematic progression deployed in The Black Cat short story. The objectives of study are 1) To indicate the types of Thematic Progression in "The Black Cat" short story and 2) to describe the realization of Thematic Progression in "The Black Cat" short story. This study was conducted in descriptive qualitative design. The data were taken from the text of "The Black Cat" short story. The source of the data in this study was The Black Cat and Other Stories book written by Edgar Allan Poe. Systemic Functional Linguistics theory proposed by Halliday (1994) was used to analyzed thematic progression in "The Black Cat" short story regarded with Textual Function. In analyzing the thematic progression, there are three kinds of thematic progression: theme reiteration, the zigzag pattern and the multiple- rheme pattern. The findings showed that the multiple- rheme pattern is the most dominant realized in 32 times (74\%), theme reiteration is the second realized in 7 times $(16,3 \%)$, and the zig-zag pattern is realized in 4 times $(9,3 \%)$ and the least dominant pattern in "The Black Cat" short story.
\end{abstract}

Keywords: textual function, thematic progression, theme and rheme, short story.

\section{Introduction}

Theme is point departure of the message (Halliday, 1994; Halliday \& Matthiessen, 2004), or the starting point of the message: what the clause is going to be about (Halliday, 1985; Eggins, 1994). It is the element which comes first in the clause. Meanwhile, rheme is part of the clause or everything that is not theme is the rheme (Eggins, 1994). Eggins (1994, p. 275) then adds "rheme is the rest of the clause after the theme. That is rheme where the theme is developed and as the writer or speaker typically departs from the familiar to head towards the unfamiliar." The rheme typically contains unfamiliar or new information (Eggins, 2004). Thus, the given information is the theme and new information is the rheme.

Thematic analysis including Theme Markdness and Thematic Progression is mostly done by some scholars. Arunsirot's (2013) explains that there are five problems of theme found in students' writing which are the problem of empty theme, the problem of the brand new theme, the problem of overuse of constant progression, the problem of empty rheme, and the problem of confusing selection of textual theme. The research conducted by Hanafiah, Yusuf, and Aswani (2018) state that Thematic analysis through Theme Markdness can be employed to evaluate students writing since Theme provides choices of what meaning to be priorisize in text. They add that the employment of Theme choices affects the readers attention. 
The purpose of thematic progression is to create a well-structured text. A wellstructured text is indicated through the connectedness between individual sentences that relate to each other.

This research attempts to find out the types of thematic progression and the realization of thematic progression is realized in "The Black Cat" short story. The purpose of thematic progression is to create a well-structured text. Thematic Progression also is used to see how the messages are delivered by the writer or the speaker in dealing with theme and rheme.

This study is expected to be beneficial both theoretically and practically. Theoretically, the findings are hoped to enlarge the knowledge of the theory of thematic progression analysis in "The Black Cat" short story and also will increase horizon about Thematic Progression. Practically, the findings are hoped to be useful and as a reference for the next research and provide an overview the reader especially the learner of English about the types and the realization of the Thematic Progression in the Short Story.

\section{Literature Review}

\subsection{Metafunction in SFL}

Systemic Functional Linguistic (SFL) has been described as a functional approach to language which explores both how people use language in different contexts, and how language is structured for use as a semiotic system. This approach is a model of grammar which constitutes part of a broad social semiotic approach to language called systemic linguistics. The term systemic refers to the view of language as a network of systems, or interrelated sets of options for making meaning; the term functional indicates that approach is Metafunctions.

Halliday (1994) maintains that the three metafunctions of language noted above operate simultaneously in the expression of meaning because certain aspects of grammar realize the ideational function, other aspects realize interpersonal function, and yet others realize the textual function.

\subsection{Textual Function}

The textual function of language is an interpretation of language in its function as a message, which is text-forming function of language (Halliday 1978, 1994). The textual function of language (clause) in its function as a message is realised by theme system of language (clause). The theme system of the clause is represented by the thematic structure of clause, which comprise two major elements: (1) Theme, and (2) Rheme (Halliday 1994: 37-67). In text, function has to do with the textual categories of discourse organisation and includes functional accounts of such questions as narrative structure, cohesion and other markers of textuality. Thematic progression, as discussed below, forms part of this functional dimension.

\subsection{Thematic Progression}

In the SFL analysis of language, patterns of Thematic choice are seen as realizing textual meanings, which in turn are the realization of Mode dimensions of the context of situation. The Theme system contributes to the realization of such meanings by offering us choices about what meanings to prioritize in a text, what to package as familiar and what as new, what to make contrastive, etc.as you have no doubt realized, the only difference between the two texts is that in the modified version the Thematic structure has been scrambled. Neither the ideational nor the interpersonal meanings have been changed, yet by 
manipulating the order in which the constituents are realized, a simple text is made quite difficult to follow.

Textual choices, such as Theme, do not introduce new content or new interpersonal dimensions into a text. But, textual choices are essential to the text's making sense. The most striking contribution of thematic choices, then, is to the internal cohesion of the text: skilful use of thematic selection results in a text which appears to hang together and make sense. A final, but very significant, contribution that Theme makes to the cohesion and coherence of a text has to do with how Thematic elements succeed each other. Three main patterns of Thematic Progression can be observed: (1) Theme reiteration, (2) The zig-zag pattern, (3) The multiple - Rheme pattern (Eggins: 2004).

\subsubsection{Theme Reiteration}

According to Eggins: 2004, Theme reiteration is one basic way to keep a text focused on simply reiterate element. As we saw with lexical cohesion, repetition is an effective means of creating cohesion. Having the same participant made Theme on regular basis provides the text with a clear focus. A text in which the Theme never varied would not only be boring to read or listen to, but would indicate a text which is going nowhere. If Theme is our point of departure, constancy of Theme would mean we are always leaving from the same spot, and that the new information introduced in the Rhemes would not be being followed up.

For instance:

Data 18

\begin{tabular}{|c|l|l|}
\hline NO & \multicolumn{1}{|c|}{ THEME } & \multicolumn{1}{c|}{ RHEME } \\
\hline $\mathbf{1}$ & But I & could not forget that black shape for months. \\
\hline $\mathbf{2}$ & I & even saw it in my dreams. \\
\hline $\mathbf{3}$ & I & began to feel sad about losing the animal. \\
\hline $\mathbf{4}$ & I & looked mostly in the poor parts of our town \\
\hline $\mathbf{5}$ & where I & went drinking. \\
\hline $\mathbf{6}$ & I & searched for another black cat, of the same size and type as Pluto. \\
\hline
\end{tabular}

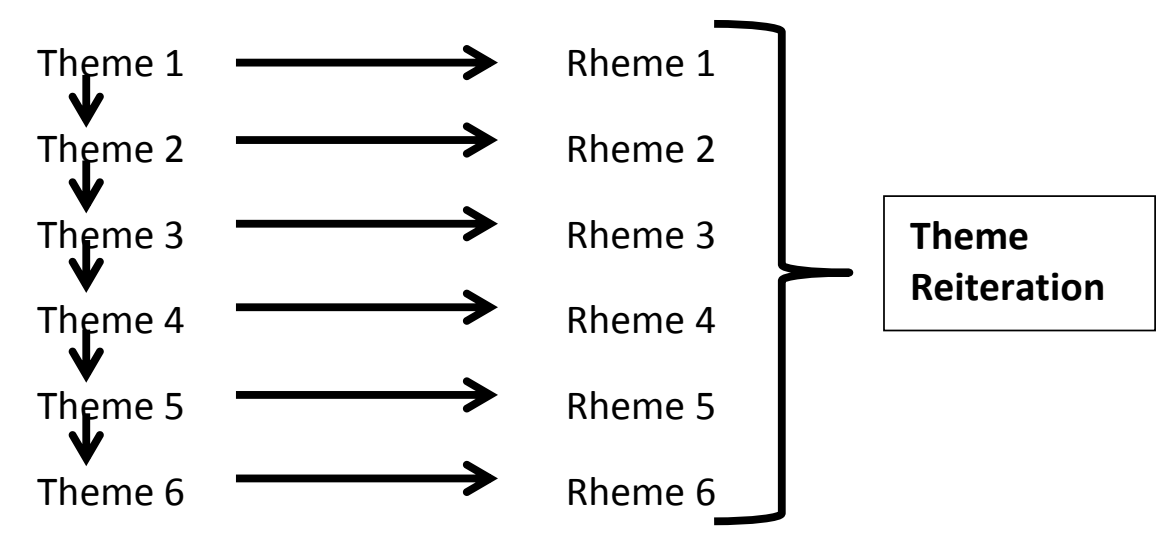

Diagram 9: Theme Reiteration

\subsubsection{The Zig-Zag Pattern}

In this pattern, an element which is introduced in the Rheme in clause gets promoted to become the Theme of clause. The zig-zag pattern achieves cohesion in the text by building on newly introduced information. This gives the text a sense of cumulative development which may be absent in the repeated Thematic pattern (Eggins: 2004). 
Thematic Progression Patterns of Short Story The Black Cat, Dewi Fatmawati, Tengku Silvana Sinar, Rohani Ganie, Muhammad Yusuf

For instance:

\begin{tabular}{|c|l|c|}
\hline \multicolumn{2}{|c|}{ Data 15 } \\
\hline NO & \multicolumn{1}{|c|}{ THEME } & RHEME \\
\hline $\mathbf{1}$ & I & was surprised to see a crowd of people next to the wall. \\
\hline 2 & They & were talking, and seemed to be quite excited. \\
\hline
\end{tabular}

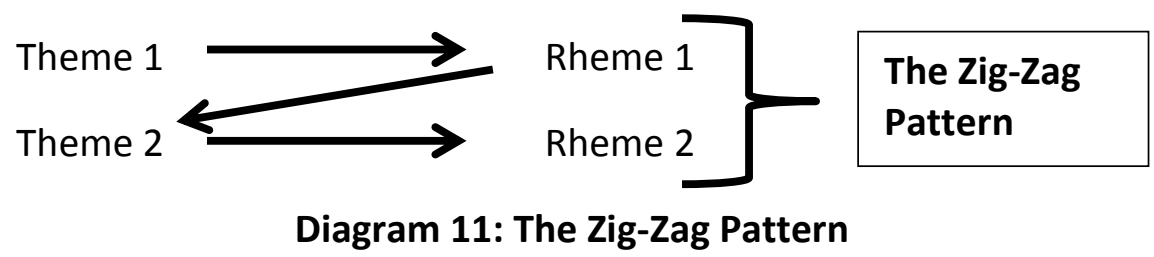

\subsubsection{The Multiple - rheme pattern}

According to Eggins (2004), the Theme of one clause introduces a number of different pieces of information, each of which is then picked up and made Theme in subsequent clause. This multiple-Rheme pattern is also common in longer expository texts. The multiple - Rheme pattern of provides the underlying organizing principle for a text, with both the zig-zag and theme reiteration strategies being used for elaborating on each of the main thematic points.

For instance:

Data 3

\begin{tabular}{|c|l|l|}
\hline NO & \multicolumn{1}{|c|}{ THEME } & \multicolumn{1}{c|}{ RHEME } \\
\hline $\mathbf{1}$ & I & married \\
\hline $\mathbf{2}$ & when I & was very young, \\
\hline $\mathbf{3}$ & and I & was happy to find that \\
\hline $\mathbf{4}$ & my wife & loved all of our animal friends \\
\hline $\mathbf{5}$ & as much as I & did. \\
\hline $\mathbf{6}$ & She & bought us the most beautiful animals. \\
\hline $\mathbf{7}$ & We & had all sorts of birds, gold fish, a fine dog and a cat. \\
\hline
\end{tabular}

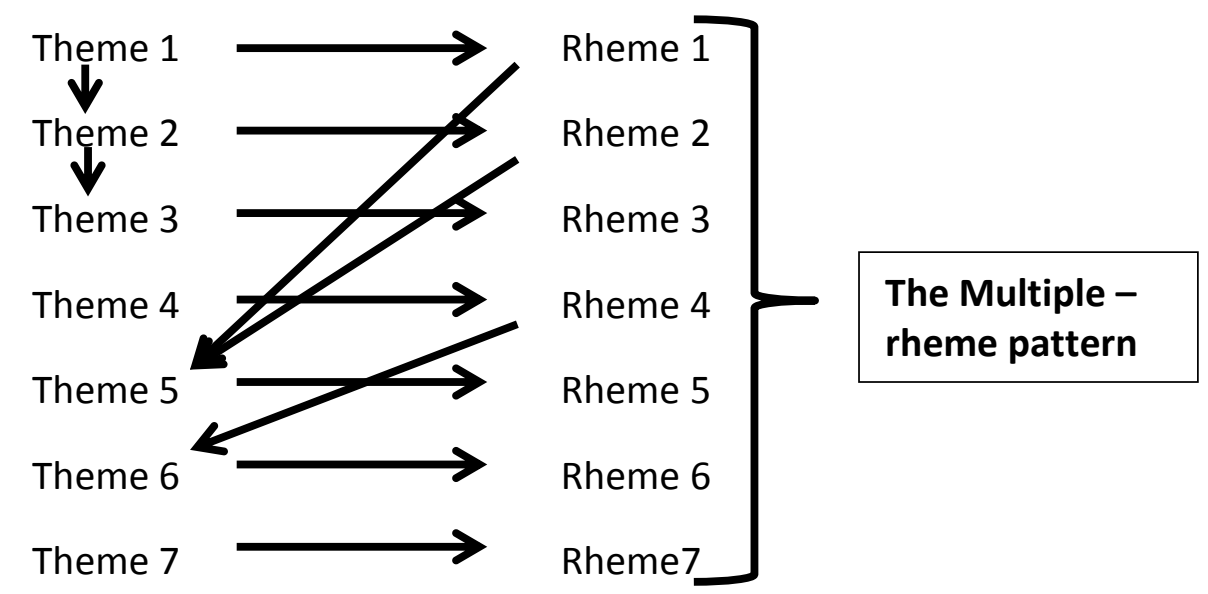

Diagram 6: The Multiple - rheme pattern 


\section{Research Method}

This research was conducted by using qualitative descriptive design. The data was taken from the text of "The Black Cat" short story in the form of clause and paragraph. The source of data in this research is Edgar Allan Poe's "The Black Cat". The data were analyzed based on Miles, Huberman and Saldana (2014) with three phases of data analysis consisting of data condensation, data display, and conclusion drawing or verification. In order to manage the data analyzing, the researcher provides some steps of analyzing the data, namely:

1. Separating the clauses into each elements.

2. Identifying the element.

3. Classifying the paragraph into theme reiteration, the zig-zag pattern, and the multiplerheme pattern.

4. Selecting the dominant thematic progression in the research articles by using the following formula: $\mathbf{n}=\mathbf{F x} / \mathbf{N} \mathbf{x 1 0 0 \%}$ (Bungin, 2005: 171-172).

Where:

$\mathbf{n} \quad=$ Percentage of types.

Fx = Total types frequency of the sub-category.

$\mathbf{N}=$ Total of all categories.

\section{Results and Discussion}

After analyzing the data, there are 316 clauses found. Then, there were three types of thematic progression found, namely theme reiteration, the zig-zag pattern and the multiple - rheme pattern. The following points would provide the analysis of the types of thematic progression found in the data.

\subsection{Theme Reiteration}

Theme reiteration is one basic way to keep a text focused to simply reiterate element. As we saw with lexical cohesion, repetition is an effective means of creating cohesion. Having the same participant make Theme on regular basis provides the text with a clear focus. A text in which the Theme never varied would not only be boring to read or listen to but would also indicate a text which is going nowhere. If Theme is our point of departure, constancy of Theme would mean we are always leaving from the same spot, and that the new information introduced in the Rhemes would not be being followed up.

There were seven occurances of Theme reiteration found in the data as in the table below:

\section{Data 18}

\begin{tabular}{|c|l|l|}
\hline NO & \multicolumn{1}{|c|}{ THEME } & \multicolumn{1}{c|}{ RHEME } \\
\hline $\mathbf{1}$ & But I & could not forget that black shape for months. \\
\hline $\mathbf{2}$ & I & even saw it in my dreams. \\
\hline $\mathbf{3}$ & I & began to feel sad about losing the animal. \\
\hline $\mathbf{4}$ & I & looked mostly in the poor parts of our town \\
\hline $\mathbf{5}$ & where I & went drinking. \\
\hline $\mathbf{6}$ & I & searched for another black cat, of the same size and type as Pluto. \\
\hline
\end{tabular}




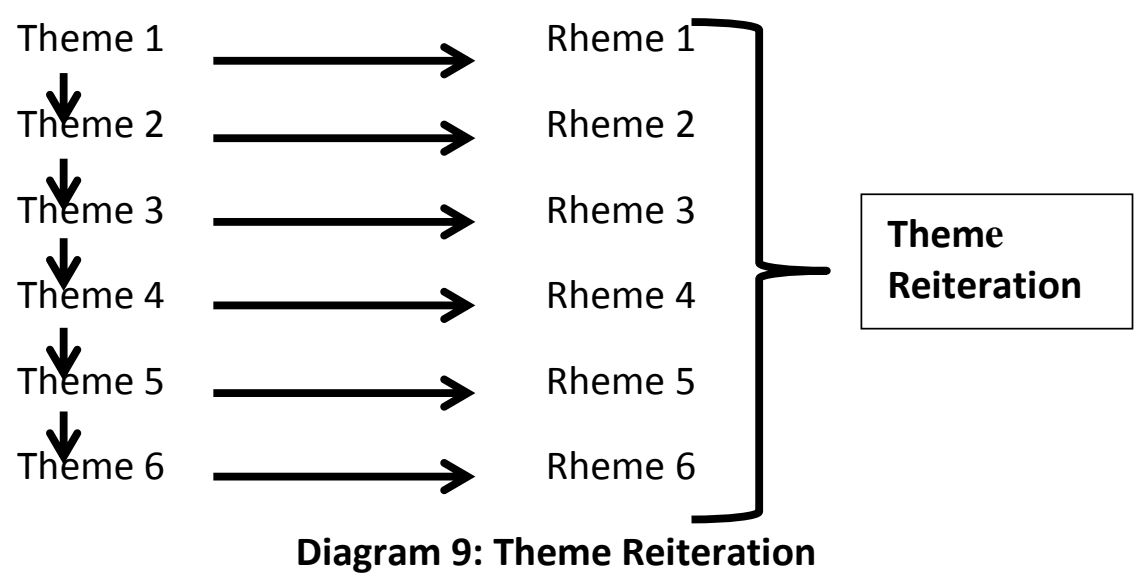

From the text above, the realization of thematic progression is appeared clearly. It can be proven from the first clause:

But I could not forget that black shape for months.

"But I" can be called Theme 1 because it is the element which serves as the point of departure of the message or the main topic which is introduced initially. "could not forget that black shape for months." can be called Rheme 1 because it is the remainder of the message or the comment about the topic so that it always comes after the topic element. Then, the second clause:

l even saw it in my dreams.

"I" can be called Theme 2 because it is the element which serves as the point of departure of the message or the main topic which is introduced initially. "even saw it in my dreams." can be called Rheme $\mathbf{2}$ because it is the remainder of the message or the comment about the topic so that it always comes after the topic element. Then, the third clause:

I began to feel sad about losing the animal.

The nominal group "I" can be called Theme $\mathbf{3}$ because it is the element which serves as the point of departure of the message or the main topic which is introduced initially. "began to feel sad about losing the animal." can be called Rheme $\mathbf{3}$ because it is the remainder of the message or the comment about the topic so that it always comes after the topic element. Then, the fourth clause:

I looked mostly in the poor parts of our town

"I" can be called Theme 4 because it is the element which serves as the point of departure of the message or the main topic which is introduced initially. "looked mostly in the poor parts of our town" can be called Rheme 4 because it is the remainder of the message or the comment about the topic so that it always comes after the topic element. Then, the fifth clause:

\section{where I went drinking.}

"where I" can be called Theme $\mathbf{5}$ because it is the element which serves as the point of departure of the message or the main topic which is introduced initially. "went drinking." can be called Rheme $\mathbf{5}$ because it is the remainder of the message or the comment about the topic so that it always comes after the topic element. Then, the sixth clause:

I searched for another black cat, of the same size and type as Pluto.

The nominal group "I" can be called Theme 6 because it is the element which serves as the point of departure of the message or the main topic which is introduced initially. "searched for another black cat, of the same size and type as Pluto." can be called Rheme 6 
because it is the remainder of the message or the comment about the topic so that it always comes after the topic element.

As the example above suggests, the patterns in which Theme 1 is repeated in Theme 2, Theme 2 is repeated in Theme 3, Theme 3 is repeated in Theme 4, Theme 4 is repeated in Theme 5, and Theme 5 is repeated in Theme 6. Each repetition is the beginning of the next clause. It indicates that each clause has information to discuss. This has the effect of maintaining a strong topical focus in the text, while avoiding simple repetition. That is why it is considered as a theme reiteration.

\subsection{The Zig-Zag Pattern}

The zig-zag pattern, an element which is introduced in the Rheme in clause gets promoted to become the Theme of clause. The zig-zag pattern achieves cohesion in the text by building on newly introduced information. This gives the text a sense of cumulative development which may be absent in the repeated Thematic pattern.

There were four occurances of the zig-zag patterns found in the data. The example is provided below:

\section{Data 15}

\begin{tabular}{|c|l|l|}
\hline NO & \multicolumn{1}{|c|}{ THEME } & \multicolumn{1}{c|}{ RHEME } \\
\hline $\mathbf{1}$ & I & was surprised to see a crowd of people next to the wall. \\
\hline $\mathbf{2}$ & They & were talking, and seemed to be quite excited. \\
\hline
\end{tabular}

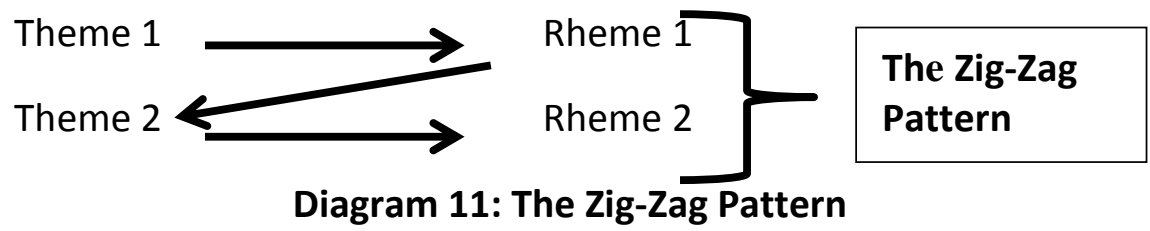

From the text above, the realization of thematic progression is appeared clearly. It can be proven from the first clause:

I was surprised to see a crowd of people next to the wall.

The nominal group "I" can be called Theme $\mathbf{1}$ because it is the element which serves as the point of departure of the message or the main topic which is introduced initially. "was surprised to see a crowd of people next to the wall." can be called Rheme 1 because it is the remainder of the message or the comment about the topic so that it always comes after the topic element. Then, the second clause:

They were talking, and seemed to be quite excited.

The nominal group "They" can be called Theme $\mathbf{2}$ because it is the element which serves as the point of departure of the message or the main topic which is introduced initially. "were talking, and seemed to be quite excited." can be called Rheme $\mathbf{2}$ because it is the remainder of the message or the comment about the topic so that it always comes after the topic element.

As the example above suggests, the pattern in which the Rheme $\mathbf{1}$ is repeated as the Theme $\mathbf{2}$ in the next clause. That is why it is considered as the zig-zag pattern.

\subsection{The Multiple- rheme pattern}

The multiple -Rheme pattern is also common in longer expository texts. This provides the underlying organizing principle for a text, with both the zig-zag and theme reiteration strategies being used for elaborating on each of the main thematic points. 
Thematic Progression Patterns of Short Story The Black Cat, Dewi Fatmawati, Tengku Silvana Sinar, Rohani Ganie, Muhammad Yusuf

There were thirty two occurances of the multiple - rheme patterns found in the data as given in the table below:

Data 4

\begin{tabular}{|c|l|l|}
\hline NO & \multicolumn{1}{|c|}{ THEME } & \multicolumn{1}{c|}{ RHEME } \\
\hline $\mathbf{1}$ & The cat & was a very large and beautiful animal. \\
\hline $\mathbf{2}$ & $\mathrm{He}$ & was black, black over, and very intelligent. \\
\hline $\mathbf{3}$ & $\mathrm{He}$ & was so intelligent \\
\hline $\mathbf{4}$ & my wife & often laughed about what \\
\hline $\mathbf{5}$ & some people & believe; \\
\hline $\mathbf{6}$ & some people & believe that \\
\hline $\mathbf{7}$ & all black cats & are evil, enemies in a cat's body. \\
\hline
\end{tabular}

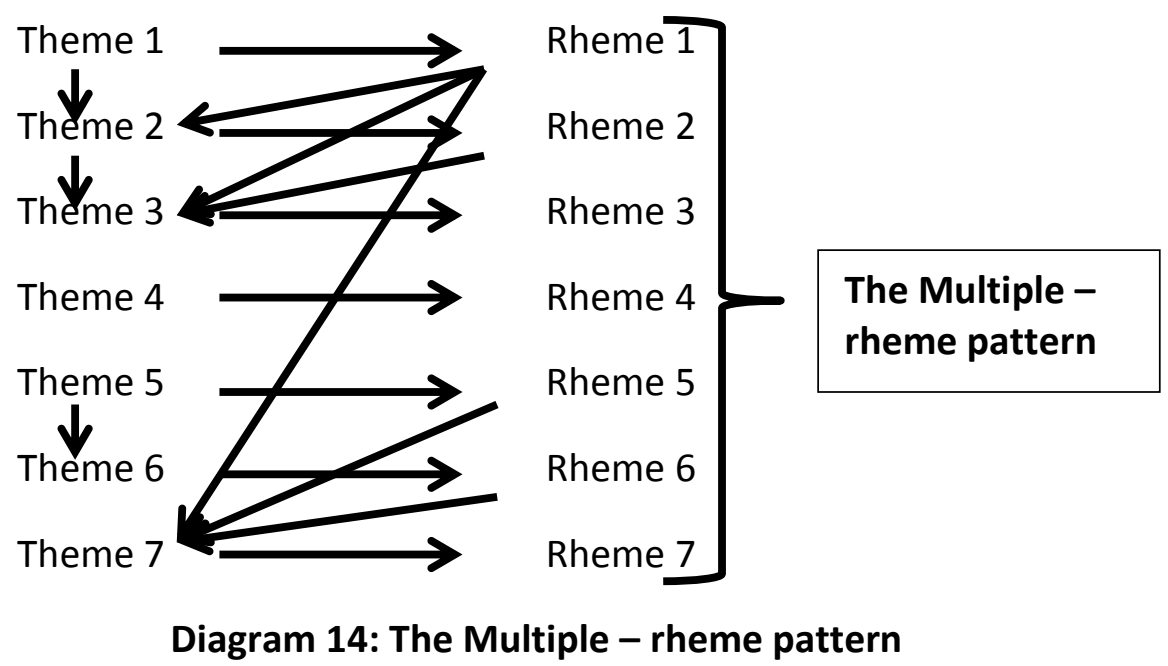

From the text above, the realization of thematic progression is appeared clearly. It can be proven from the first clause:

The cat was a very large and beautiful animal.

The nominal group "The cat" can be called Theme 1 because it is the element which serves as the point of departure of the message or the main topic which is introduced initially. "was a very large and beautiful animal." can be called Rheme $\mathbf{1}$ because it is the remainder of the message or the comment about the topic so that it always comes after the topic element. Then, the second clause:

He was black, black over, and very intelligent.

The nominal group "He" can be called Theme $\mathbf{2}$ because it is the element which serves as the point of departure of the message or the main topic which is introduced initially. "was black, black over, and very intelligent." can be called Rheme $\mathbf{2}$ because it is the remainder of the message or the comment about the topic so that it always comes after the topic element. Then, the third clause:

He was so intelligent.

"He" can be called Theme 3 because it is the element which serves as the point of departure of the message or the main topic which is introduced initially. "was so intelligent" can be called Rheme $\mathbf{3}$ because it is the remainder of the message or the comment about the topic so that it always comes after the topic element. Then, the fourth clause: 
that my wife often laughed about what

The nominal group "my wife" can be called Theme $\mathbf{4}$ because it is the element which serves as the point of departure of the message or the main topic which is introduced initially. "often laughed about what" can be called Rheme $\mathbf{4}$ because it is the remainder of the message or the comment about the topic so that it always comes after the topic element. Then, the fifth clause:

some people believe;

The nominal group "some people" can be called Theme $\mathbf{5}$ because it is the element which serves as the point of departure of the message or the main topic which is introduced initially. "believe;" can be called Rheme 5 because it is the remainder of the message or the comment about the topic so that it always comes after the topic element. Then, the sixth clause:

some people believe that

The nominal group "some people" can be called Theme 6 because it is the element which serves as the point of departure of the message or the main topic which is introduced initially. The process "believe that" can be called Rheme 6 because it is the remainder of the message or the comment about the topic so that it always comes after the topic element. Then, the seventh clause:

all black cats are evil, enemies in a cat's body.

The nominal group "all black cats" can be called Theme 7 because it is the element which serves as the point of departure of the message or the main topic which is introduced initially. "are evil, enemies in a cat's body." can be called Rheme 7 because it is the remainder of the message or the comment about the topic so that it always comes after the topic element.

As the example above suggests, the patterns in which Rheme $\mathbf{1}$ is repeated as Theme 2, Theme 3, and Theme $\mathbf{7}$ in the next clause. Rheme $\mathbf{2}$ is also repeated as Theme $\mathbf{3}$ in the next clause. Rheme $\mathbf{5}$ is repeated as Theme $\mathbf{7}$ in the next clause. Rheme $\mathbf{6}$ is also repeated as Theme $\mathbf{7}$ in the next clause. While Theme $\mathbf{1}$ is repeated in Theme 2. Theme $\mathbf{2}$ is repeated in Theme 3. And Theme 5 is repeated in Theme 6. It may include some different information which may be taken up as theme in some subsequent clauses. It also merge between theme reiteration and the zig-zag pattern. That is why it is considered as the multiple-rheme pattern.

\section{Conclusion}

After analyzing the data, the conclusion could be drawn there are three types of thematic progression from the text "The Black Cat" short story which can be found in "The Black Cat and Other Stories" Book they were: theme reiteration, the zig-zag pattern and the multiple-rheme pattern.

They were realized with a different pattern of a paragraph as its function or in other words they found their thematic progression in a different form as it used to be. As Eggins (2004) states that thematic progression should be realized in paragraph of text. On this matter the paragraph realized in a different types of pattern which show the type of thematic progression itself.

From the three types of thematic progression that had been found from the text, theme reiteration involved the types of thematic progression because of Theme is point of departure, constancy of Theme would mean always leaving from the same spot, it should be realized in thematic progression if it follows its function. The zig-zag pattern involved the 
types of thematic progression because of Rheme in clause gets promoted to become the Theme of clause, it should be realized in thematic progression if it follows its function. The multiple - rheme pattern involved the types of thematic progression because of there is elaborating the zig-zag pattern and theme reiteration in the paragraph, it should be realized in thematic progression if it follows its function.

\section{References}

Arunsirot, S. (2013). An analysis of textual metafunction in Thai EFL students' writing, Research on Youth and Language, 7(2), 160-174.

Astuti, W. (2018). Thematic structure of sport texts in waspada newspaper. Proceedings of Annual International Conference on Language and Literature. Medan: UISU.

Bungin, B. (2005). Metode Penelitian Kuantitatif. Jakarta: Prenadamedia.

Eggins, S. (1994). An Introduction to Systemic Functional Linguistics. London: Continuum.

Eggins, S. (2004). An Introduction to Systemic Functional Linguistic (2 ${ }^{\text {nd }}$ Edition). London: Continuum.

Halliday, M.A.K. (1985). An Introduction to Functional Grammar. London: Edward Arnold.

Halliday, M.A.K. (1994). An introduction to Functional Grammar (2 ${ }^{\text {nd }}$ edition). London: Edward Arnold.

Halliday, M.A.K. \& Matthiesen, C.M.I.M. (2004). Introduction to Functional Grammar (3 ${ }^{\text {rd }}$ Edition). New York: Routledge.

Sinar, T. S. (2002). An Introduction to Systemic-functional Linguistic-oriented Discourse Analysis. Deezed Consult.

Suhadi, J. (2015). Course In English Functional Grammar. Medan: LPPM UISU Press.

Wharry, D. (1991). The Black Cat and Other Stories by Edgar Allan Poe. England: Pearson Education Limited in association with Penguin Books Ltd. Retrieved from http://www.e4thai.com/e4e/images/pdf/level\%203\%20-\%20Black\%20Cat.pdf (October 2018). 